\title{
Motility activation and second messenger signalling in spermatozoa from rat cauda epididymidis
}

\author{
M. A. Wade, R. C. Jones, R. N. Murdoch and R. J. Aitken \\ Discipline of Biological Sciences, School of Environmental and Life Sciences, University of Newcastle, \\ NSW, 2308, Australia
}

This study examined molecular mechanisms involved in the activation of motility in spermatozoa from the cauda epididymidis of rats. A 1.05-fold dilution of semen from the cauda epididymidis with 300 mmol sucrose $\mathrm{I}^{-1}$ did not activate motility in spermatozoa. Addition of dibutyryl cAMP, pentoxifylline or $\mathrm{Ca}^{2+}$ to the sucrose activated motility in the short term $(<30-60 \mathrm{~min})$. A fivefold dilution of semen from the cauda epididymidis with a modified Tyrode's medium (BWW) activated and sustained vigorous motility that could not be attenuated with kinase inhibitors. This motility was associated with a transient increase in intracellular cAMP during the first $60 \mathrm{~s}$ of activation. Lower motility was activated in $\mathrm{Ca}^{2+}$-deficient media but this was not associated with an increase in cAMP. A fivefold dilution with plasma from the cauda epididymidis did not activate motility. The addition of
$\mathrm{Ca}^{2+}$ to the sucrose induced an increase in cAMP of similar duration but lower magnitude to that associated with dilution in BWW. The results from this study indicate that the cAMP and $\mathrm{Ca}^{2+}$ signal transduction pathways are involved in activation of sperm motility, and that the increase in intracellular cAMP in rat spermatozoa from the cauda epididymidis undergoing motility activation is $\mathrm{Ca}^{2+}$-dependent. This is the first study to report a $\mathrm{Ca}^{2+}$ dependent increase in cAMP associated with motility activation in immotile mammalian spermatozoa. In light of these data, a model is proposed whereby cAMP and $\mathrm{Ca}^{2+}$ act as synarchic messengers, initiating a signal transduction cascade, which is independent of protein kinase A-mediated phosphorylation of flagella proteins in immotile spermatozoa from the cauda epididymidis.

\section{Introduction}

Spermatozoa are stored in extratesticular ducts in an immotile state in many animals and their motility is activated on release from the ducts, by dilution. The mechanisms involved in the activation process appear to be resolved for a number of externally fertilizing species. In sea urchin spermatozoa, sodium-proton $\left(\mathrm{Na}^{+}-\mathrm{H}^{+}\right)$ exchangers in the plasma membrane are activated by a voltage change that occurs at dilution. This event, which is associated with an increase in intracellular $\mathrm{pH}\left(\mathrm{pH}_{(\mathrm{i})}\right)$ and activation of axonemal dynein-ATPases, can be blocked by depolarization with a high external $\mathrm{K}^{+}\left(\mathrm{K}^{+}(\mathrm{e})\right)$ concentration (Christen et al., 1982). Adenylyl cyclase in this species is activated by hyperpolarization (Beltran et al., 1996) and the subsequent increase in adenosine $3^{\prime}, 5^{\prime}$-cyclic monophosphate (cAMP) is associated with activation of motility, and phosphorylation of specific flagellar proteins (Bracho et al., 1998). In trout spermatozoa, high $\mathrm{K}^{+}{ }_{(\mathrm{e})}$ also regulates membrane polarity and motility can be activated by a reduction in the concentration of this ion or by the addition of divalent cations (Boitano and Omoto, 1991). Activation is

Email: bimw@alinga.newcastle.edu.au accompanied by an increased amount of CAMP and phosphorylation of a $15 \mathrm{kDa}$ membrane protein (for reviews, see Hamamah and Gatti, 1998; Darszon et al., 1999). In cyprinid fishes such as carp, osmotic pressure is an important regulator of activation. Hypo-osmotic shock and reduction in $\mathrm{K}^{+}$(e) concentration hyperpolarizes the plasma membrane. This alteration in polarity is thought to permit an influx of $\mathrm{Ca}^{2+}$, essential to activate motility in these cells, in which CAMP apparently has no role (Krasznai et al., 2000).

Mechanisms involved in activation of motility in mammalian spermatozoa are less well defined. The effect of dilution on the sperm membrane is poorly characterized. However, changes in $\mathrm{Ca}^{2+}, \mathrm{K}^{+}, \mathrm{Na}^{+}$and $\mathrm{H}^{+}$status have been implicated in the activation process, as have a number of other factors (for review, see Jones and Murdoch, 1996). These factors include a reduction in viscoelasticity of the extracellular fluid surrounding quiescent spermatozoa at activation (Usselman and Cone, 1983), activation of sperm adenylyl cyclase by bicarbonate ions (Okamura et al., 1985), protein kinase A (PKA)-mediated phosphorylation of flagella proteins (Tash and Bracho, 1998) and by reactive oxygen species (ROS), particularly hydrogen peroxide $\left(\mathrm{H}_{2} \mathrm{O}_{2}\right)$ (Aitken, 2000). 
There is general agreement that the cyclic nucleotide adenosine $3^{\prime}, 5^{\prime}$-cyclic monophosphate (cAMP) plays a role in regulating sperm function, including motility and there is also evidence to suggest that an increase in cAMP is associated with activation of motility in spermatozoa from the cauda epididymidis of hamsters (Morton et al., 1974) and rats (Armstrong et al., 1994). $\mathrm{Ca}^{2+}$ also activates motility in spermatozoa from the cauda epididymidis from both these species (Morton et al., 1974; Armstrong et al., 1994).

An absolute prerequisite for the study of activation of motility is a viable population of spermatozoa that have never been exposed to primary activation stimuli. The present study has followed an experimental paradigm whereby immotile spermatozoa were collected directly from the cauda epididymidis, to avoid non-specific activation. The purpose of this investigation was to use this methodology to examine the mechanisms by which motility is activated in populations of spermatozoa from the cauda epididymidis, with particular emphasis on the dynamic interactions between cAMP and $\mathrm{Ca}^{2+}$ in controlling this event.

\section{Materials and Methods}

\section{Animals}

Outbred sexually mature Wistar male rats aged 36 months were used in all experiments. The animals were housed two per cage in the Central Animal House Facility, University of Newcastle with a $12 \mathrm{~h}$ light: $12 \mathrm{~h}$ dark cycle and food and water were available ad libitum. Animals were killed with carbon dioxide inhalation. The University of Newcastle Animal Care and Ethics Committee approved the animal experimentation.

\section{Collection and treatment of semen from the cauda epididymidis}

Semen from the cauda epididymidis was collected into a siliconized $40 \mu \mathrm{l}$ microcapillary tube (Bacto Laboratories, Sydney) by back-flushing the distal cauda epididymidis using paraffin oil saturated with water. Semen was dispensed under paraffin oil saturated with water and maintained at $34^{\circ} \mathrm{C}$ in a siliconized embryo dish. The spermatozoa in this semen were immotile when examined under a stereomicroscope. Epididymal plasma was separated from spermatozoa by centrifuging the semen in a microcapillary tube for 30 min in a haematocrit centrifuge (Gelman Hawksley Ltd, Sussex). Seminal vesicle fluid was collected into a $10 \mu \mathrm{l}$ microcapillary tube (Bacto Laboratories, Sydney) by clamping the coagulating gland and puncturing the collecting duct of the seminal vesicle. Prostatic fluid was collected from the penis of anaesthetized rats while electrically stimulating the ventral lobes of the prostate gland at $20 \mathrm{~V}$ and a frequency of $7 \mathrm{~Hz}$ (Harvard Kymograph Apparatus Ltd, Kent).

\section{Activation of sperm motility}

Two different methods of activating sperm motility were used. The first method involved diluting $1 \mu \mathrm{l}$ samples of semen from the cauda epididymidis (containing $1.8-2.2 \times 10^{9}$ spermatozoa $\mathrm{ml}^{-1}$ ) fivefold with a modified Tyrode's medium (BWW: $95 \mathrm{mmol} \mathrm{NaCl}^{-1}$, $4.8 \mathrm{mmol} \mathrm{KClI}^{-1}, 1.7 \mathrm{mmol} \mathrm{CaCl}_{2} \mathrm{I}^{-1}, 1.2 \mathrm{mmol}$ $\mathrm{KH}_{2} \mathrm{PO}_{4} \mathrm{I}^{-1}, \quad 1.2 \mathrm{mmol} \quad \mathrm{MgSO}_{4} \mathrm{I}^{-1}, \quad 24.88 \mathrm{mmol}$ $\mathrm{NaHCO}_{3} \mathrm{I}^{-1}, \quad 5.55 \mathrm{mmol}$ glucose $\mathrm{I}^{-1}, \quad 0.27 \mathrm{mmol}$ pyruvic acid $\mathrm{I}^{-1}, 0.25 \mathrm{mmol}$ lactic acid $\mathrm{I}^{-1}, 0.5$ units penicillin $\mathrm{ml}^{-1}, 0.5 \mu \mathrm{g}$ streptomycin $\mathrm{ml}^{-1}, 20 \mathrm{mmol}$ Hepes buffer $\mathrm{I}^{-1}, 0.3 \%$ BSA; $300 \mathrm{mOsmol}^{\prime-1}$ ) (Biggers et al., 1971). Samples (1 $\mu \mathrm{l})$ of semen from the cauda epididymidis were also diluted fivefold with epididymal plasma or fluid from the prostatic or seminal vesicles. The second method, adapted from the procedure used by Pholpramool et al. (1985), Clulow et al. (1992), Armstrong et al. (1994) and Murdoch et al. (1999), used a volumetric pipette to deliver various chemical reagents in $50 \mathrm{nl}$ of $300 \mathrm{mOsmol}$ sucrose $\mathrm{I}^{-1}$ to $1 \mu \mathrm{l}$ samples of semen from the cauda epididymidis. This dilution (1.05-fold) with the sucrose solution alone was examined in all studies and did not activate sperm motility. Pipettes with hermetically sealed ends were used to mix the sucrose solution with the semen sample. Motility of samples was assessed under a microscope using reflected light, before mixing, within $1 \mathrm{~min}$ after mixing, then every 5-15 min, depending on the experiment, at $37^{\circ} \mathrm{C}$. The period over which samples were monitored was dependent on the reagent; the minimum time was $30 \mathrm{~min}$ and the maximum time $60 \mathrm{~min}$. During monitoring, the temperature of the sample was maintained by a laboratory warming tray or stage warmer (Reichert, Vienna). At the end of the period of monitoring all samples were assessed for viability by a fivefold dilution with BWW. The ability of kinase inhibitors to prevent the attenuation of motility was examined by either including them in the BWW used to carry out fivefold dilutions or by diluting a $1 \mu \mathrm{l}$ sample of semen from the cauda epididymidis by 1.05 -fold with $300 \mathrm{mOsmol}_{\text {sucrose }}{ }^{-1}$ containing $20 \mu \mathrm{mol} \mathrm{H} 891^{-1}$, and then further diluting the sample fivefold with BWW containing $100 \mu \mathrm{mol} \mathrm{H} 89 \mathrm{I}^{-1}$ at 0,15 and $30 \mathrm{~min}$ after the initial addition of the inhibitor. The concentrations of substances stated represent the final concentrations after solutions were mixed with $1 \mu$ l of semen from the cauda epididymidis. The optimal concentrations for dibutyryl cAMP (dbcAMP), pentoxifylline (PTX) and $\mathrm{Ca}^{2+}$ were determined from dose-response experiments.

\section{Assessment of sperm motility}

The criterion for assessing sperm motility was the 'swirling' motion of the sample, which was scored using a scale of $0-10$, where 0 represents an inactive sample and 10 represents a sample of maximum activity (Pholpramool et al., 1985; Clulow et al., 1992; 
Table 1. Reagents tested for ability to activate motility when a $1 \mu \mathrm{l}$ sample of semen from the rat cauda epididymidis was diluted 1.05 -fold with $300 \mathrm{mmol}$ sucrose $1^{-1}$ containing the reagent

\begin{tabular}{|c|c|c|}
\hline Reagent & Concentration & Motility activation \\
\hline Dibutyryl cAMP & $2,4,8,16 \mathrm{mmol}^{-1}$ & + \\
\hline Dibutyryl cAMP/glucose & $16,20 \mathrm{mmol} 1^{-1}$ & + \\
\hline Dibutyryl cAMP/acetate & $16,20 \mathrm{mmol}^{-1}$ & + \\
\hline Dibutyryl cAMP/lactate & $16,10 \mathrm{mmol} 1^{-1}$ & + \\
\hline Pentoxifylline & $2,4,8,16 \mathrm{mmol} 1^{-1}$ & + \\
\hline Calcium $\left(\mathrm{Ca}^{2+}\right)$ & $2,4,8,16 \mathrm{mmol} 1^{-1}$ & + \\
\hline 1,3,7-trimethylxanthine (caffeine) & $2,4,8 \mathrm{mmol}^{-1}$ & + \\
\hline Dibutyryl cGMP & $5,10,15 \mathrm{mmol} 1^{-1}$ & - \\
\hline Phorbol-12-myristate-13-acetate & $0.25,2.5,25 \mu \mathrm{mol} 1^{-1}$ & - \\
\hline Bicarbonate $\left(\mathrm{HCO}_{3}^{-}\right)$ & $10,20 \mathrm{mmol}^{-1}$ & - \\
\hline Sodium chloride & $1,3,5,10,15,20,40,60 \mathrm{mmol}^{-1}$ & - \\
\hline Glucose & $5,10,20,40,60 \mathrm{mmol}^{-1}$ & - \\
\hline Acetate & $10,20 \mathrm{mmol}^{-1}$ & - \\
\hline Lactate & $10 \mathrm{mmol} 1^{-1}$ & - \\
\hline Forskolin & $25,50,100,200,400 \mu \mathrm{mol} 1^{-1}$ & - \\
\hline Cholera toxin & $10 \mu \mathrm{g} \mathrm{m}^{-1}$ & - \\
\hline Pertussis toxin & $1,10 \mu \mathrm{g} \mathrm{ml}^{-1}$ & - \\
\hline Hydrogen peroxide $\left(\mathrm{H}_{2} \mathrm{O}_{2}\right)$ & $5 \times 10^{-4}, 0.05,5,500 \mu \mathrm{mol} 1^{-1}$ & - \\
\hline Hydrogen peroxide $\left(\mathrm{H}_{2} \mathrm{O}_{2}\right)$ & $2.5,5,20,30,40 \mathrm{mmol}^{-1}$ & - \\
\hline $\mathrm{NADPH}$ & $1.25,2.5,5 \mathrm{mmol}^{-1}$ & - \\
\hline
\end{tabular}

Values shown represent final concentrations.

+: motility activation; -: no motility activation. Motility was assessed within 1 min after dilution and then every 5-15 min for 30 or $60 \mathrm{~min}$, depending on the reagent. The viability of the samples after monitoring was examined by a fivefold dilution with BWW medium. A minimum of six replicates was carried out when the test reagent activated sperm motility. A minimum of three replicates was carried out when the test reagent did not activate sperm motility.

Armstrong et al., 1994; Murdoch et al., 1999). A fivefold dilution with BWW, which consistently achieved motility scores of 9-10, was used as a reference, against which all motility was scored. The scoring variance between experiments, achieved by a single scorer, is estimated to be approximately $10 \%$.

\section{Concentration of CAMP in spermatozoa}

Samples of spermatozoa $\left(1.4-1.8 \times 10^{9}\right.$ spermatozoa $\mathrm{ml}^{-1}$ for activated and 1.8-2.2 $\times 10^{9}$ spermatozoa ml-1 non-activated samples) were homogenized in trichloroacetic acid $(6 \% \mathrm{w} / \mathrm{v})$ with a disposable polypropylene homogenization pestle (Scientific Specialties Incorporated, Lodi, CA) at $4{ }^{\circ} \mathrm{C}$, and extracted for $10 \mathrm{~min}$. After extraction, samples were centrifuged at $11600 \mathrm{~g}$ (10 $\mathrm{min}$ at $4^{\circ} \mathrm{C}$ ) using a Clements Orbital 100 bench centrifuge. Supernatants were extracted with 10 volumes of diethyl ether saturated with water, dried under nitrogen at $50^{\circ} \mathrm{C}$ and stored at $-70^{\circ} \mathrm{C}$ until assayed. Immediately before the assay, samples were reconstituted in $150 \mu \mathrm{l}$ acetate buffer $\left(0.05 \mathrm{~mol}\right.$ sodium acetate $\mathrm{I}^{-1}, \mathrm{pH} 5.8$, $0.02 \% \mathrm{w} / \mathrm{v}$ bovine serum albumin and $0.01 \% \mathrm{w} / \mathrm{v}$ Germall2). cAMP was then determined using the nonacetylation procedure provided by the Biotrak cAMP enzyme immunoassay system (Amersham Pharmacia Biotech, Castle Hill) in accordance with the manufacturer's guidelines. Absorbances were read at $450 \mathrm{~nm}$ on a microplate reader (Bio-Rad, Hercules, CA).

\section{Statistical analyses}

For studies of activation of sperm motility, ANOVA was used to compare the effect of activating reagents on sperm motility at a selected time point $(10 \mathrm{~min})$. Data from cAMP analyses were transformed to the natural log where necessary and assessed using ANOVA and the Tukey Honest Significant Difference (HSD) test. Statistica 5.5 software (StatSoft Pacific Pty Ltd, Melbourne) was used for these analyses. Data are shown as mean \pm SEM; the SEM is calculated from the variance among animals.

\section{Results}

\section{Activation of sperm motility with 1.05-fold dilution}

It was confirmed that diluting a $1 \mu \mathrm{l}$ sample of semen from the cauda epididymidis with $50 \mathrm{nl}$ of $300 \mathrm{mmol}$ sucrose $^{-1}$ (1.05-fold) did not activate sperm motility. The effects of including various reagents in the sucrose vehicle are summarized (Table 1). Only the inclusion of dbcAMP, PTX, caffeine or $\mathrm{Ca}^{2+}$ activated sperm motility. Dose-response experiments were carried out and the concentrations of dbcAMP, PTX and $\mathrm{Ca}^{2+}$ that gave 
(a)

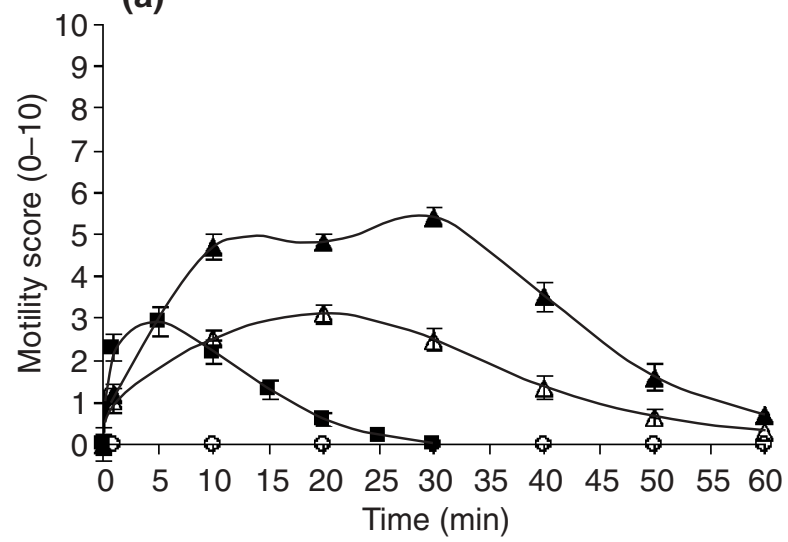

(c)

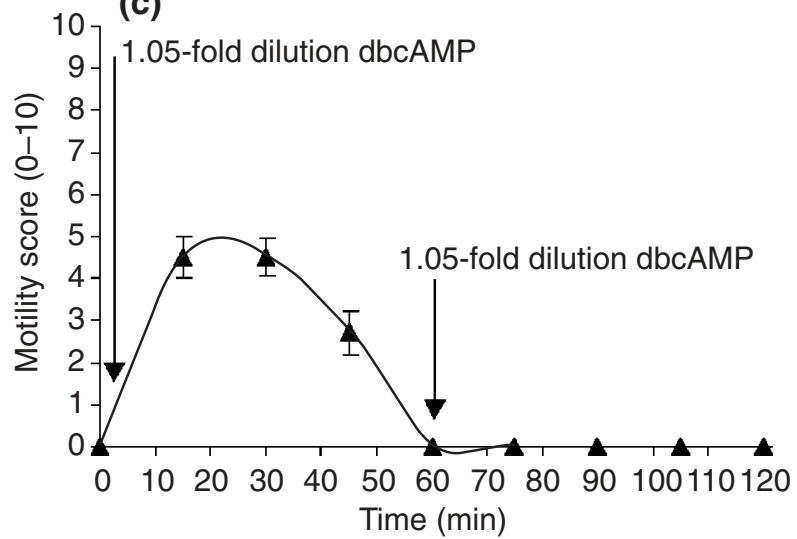

(b)

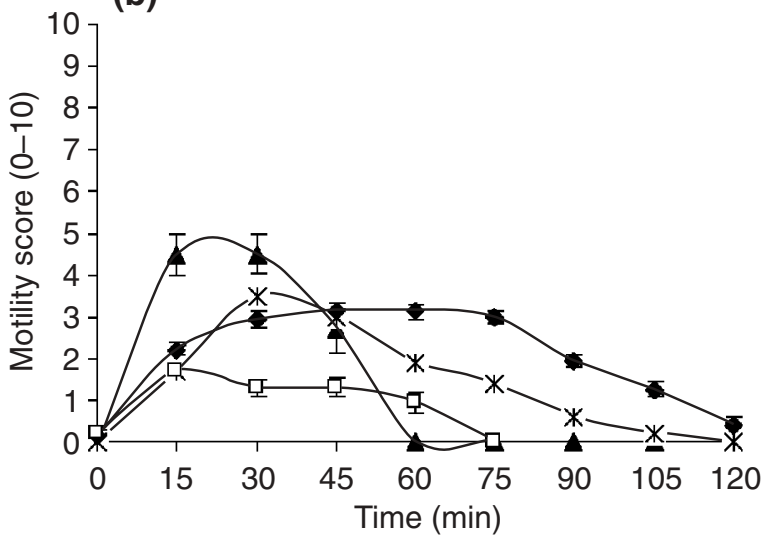

(d)

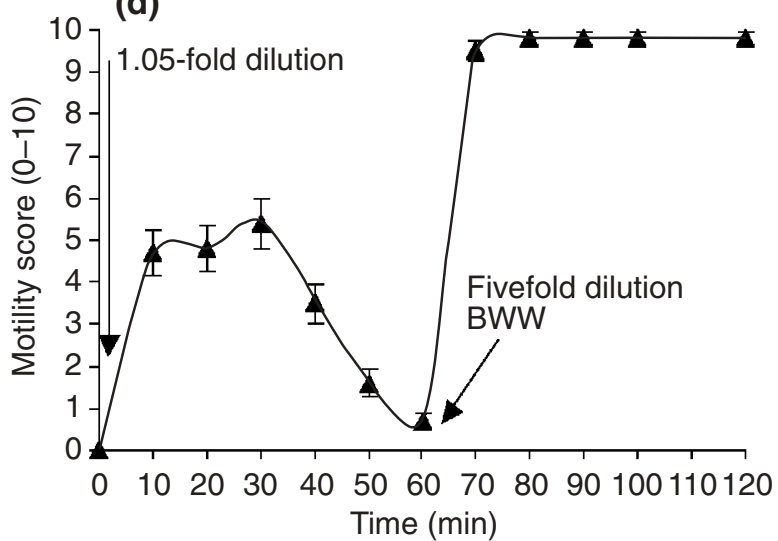

Fig. 1. Activation of sperm motility in $1 \mu \mathrm{l}$ of semen from the rat cauda epididymidis diluted 1.05 -fold with $300 \mathrm{mmol}$ sucrose $1^{-1}$ containing (a) dibutyryl $\operatorname{cAMP}(\mathbf{\Lambda})$ or pentoxifylline $(\triangle)$ at final concentrations of $16 \mathrm{mmol}^{-1}$ or $^{-2+}(\boldsymbol{\square})$ at a final concentration of $8 \mathrm{mmol}^{-1}$ or sucrose alone $(\bigcirc)$; (b) dibutyryl cAMP $(\mathbf{\Lambda})$ at a final concentration of $16 \mathrm{mmol} 1^{-1}$ alone or combined with glucose $(x)$ or acetate $(\bullet)$ at a final concentration of $20 \mathrm{mmol} 1^{-1}$ or combined with lactate $(\square)$ at a final concentration of $10 \mathrm{mmol}^{-1}$; (c) $16 \mathrm{mmol}$ dibutyryl cAMP $1^{-1}$, at $0 \mathrm{~min}$ and again at $60 \mathrm{~min}$; (d) 16 mmol dibutyryl cAMP $1^{-1}$ at $0 \mathrm{~min}$ and then further diluted fivefold with modified Tyrode's medium (BWW) at $60 \mathrm{~min}$. Values are mean \pm SEM for (a) 5 ; (b) $6(x, \bullet), 5$ ( $\square)$; (c) 7 and (d) 5 animals.

the optimal effect were chosen for further analyses (Fig. 1). The inclusion of dibutyryl cGMP (dbcGMP), other salts, energy substrates, reactive oxygen species, such as those generated with nicotinamide adenine dinucleotide phosphate, reduced nicotinamide adenine dinucleotide phosphate (NADPH) or hydrogen peroxide $\left(\mathrm{H}_{2} \mathrm{O}_{2}\right)$, forskolin, cholera (Vibrio cholerae) toxin or pertussis (Bordetella pertussis) toxin did not activate sperm motility.

Activation of sperm motility by $\mathrm{Ca}^{2+}$ was rapid, but declined and ceased within 30 min (Fig. 1a). dbcAMP activated stronger sperm motility than $\mathrm{Ca}^{2+}(P<0.05)$ and this was sustained longer but spermatozoa became virtually immotile by approximately $60 \mathrm{~min}$. PTX activated lower sperm motility than dbcAMP $(P<0.05)$, which also declined by approximately $60 \mathrm{~min}$ (Fig. 1a). Glucose, acetate and lactate were each included with the dbcAMP, to determine whether the decline in motility within $60 \mathrm{~min}$ of activation with dbcAMP was due to a lack of energy substrate. The inclusion of glucose or acetate extended the period of sperm motility to approximately $120 \mathrm{~min}$. When lactate was used as the potential energy substrate, sperm motility was lower and ceased at $75 \mathrm{~min}$ (Fig. 1b). Glucose, acetate or lactate alone did not activate motility (data not shown). After completion of the response to an initial activation by dbcAMP, it was not possible to re-activate sperm motility even by another addition of $16 \mathrm{mmol}$ dbcAMP $1^{-1}$ at 60 min (Fig. 1c). However, the spermatozoa were viable and responded to a fivefold dilution with BWW at $60 \mathrm{~min}$ by showing strong sperm motility (Fig. 1d).

\section{Activation of sperm motility with fivefold dilution}

Vigorous motility was activated in spermatozoa by diluting a $1 \mu \mathrm{l}$ sample of semen from the cauda epididymidis fivefold with BWW (Fig. 2a) or prostatic fluid (Fig. 2b). Sperm motility activated by BWW was maintained for hours (data not shown). When $\mathrm{Ca}^{2+}$ was omitted from the BWW, spermatozoa were less 
(a)

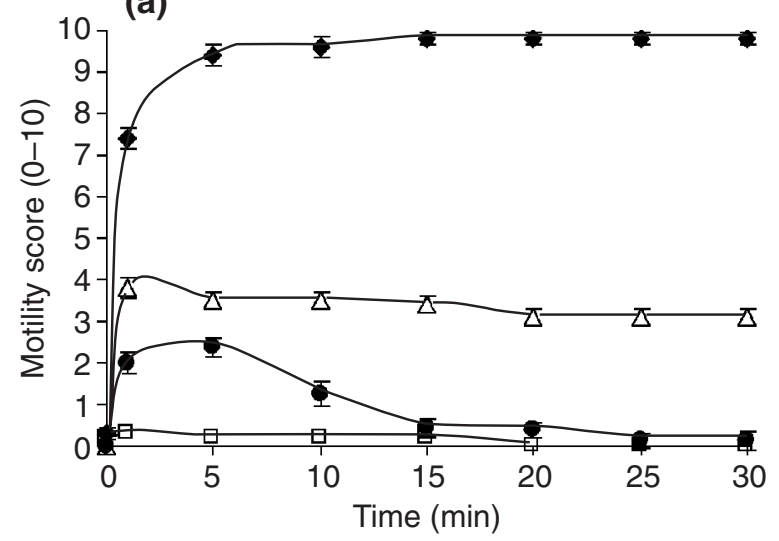

(c)

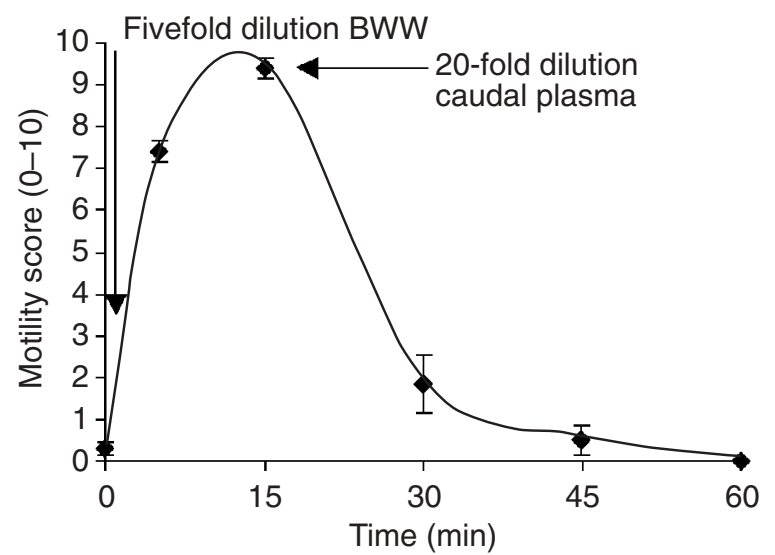

(b)

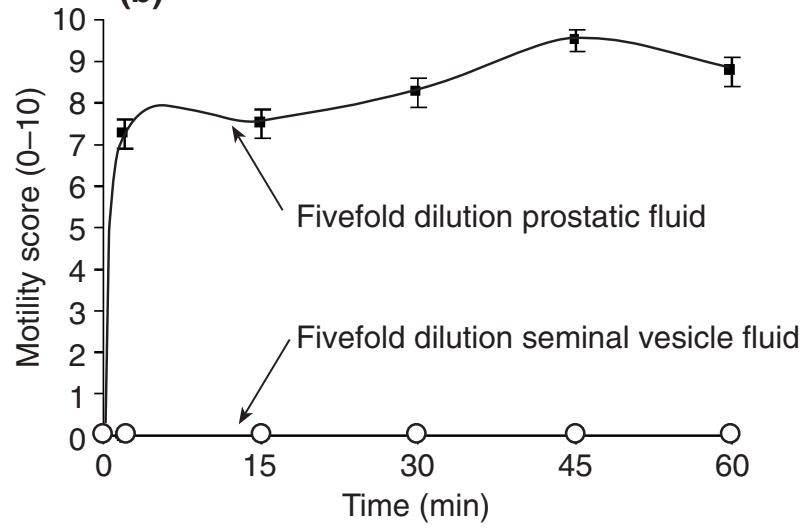

(d)

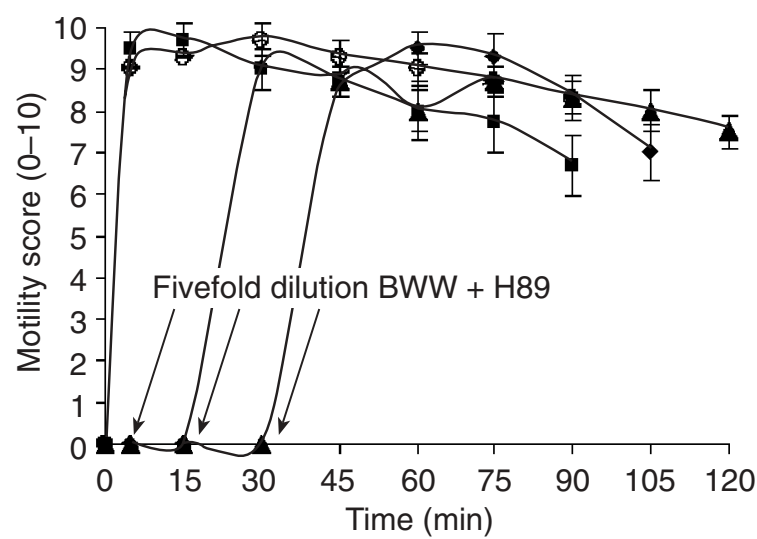

Fig. 2. Activation of sperm motility in $1 \mu \mathrm{l}$ of semen from the cauda epididymidis by fivefold dilution (a) with modified Tyrode's medium (BWW) containing $1.8 \mathrm{mmol} \mathrm{Ca}{ }^{2+} 1^{-1}(\diamond), 0 \mathrm{mmol} \mathrm{Ca}{ }^{2+} 1^{-1}(\triangle)$ or with $350 \mathrm{mOsmol} \mathrm{Hepes-sucrose} \mathrm{solution} 1^{-1}(\bullet)$ or with plasma from the cauda epididymidis ( $\square$ ); (b) with prostatic fluid or seminal vesicle fluid; (c) with BWW and subsequent inhibition of motility in the same sample with a further 20 -fold dilution with plasma from the cauda epididymidis (motility ceased at $60 \mathrm{~min}$ ). (d) The effect of the protein kinase inhibitor $\mathrm{H} 89$ on sperm motility in $1 \mu$ l of semen from the cauda epididymidis diluted first 1.05 -fold with $300 \mathrm{mmol}$ sucrose $1^{-1}$ containing $20 \mu \mathrm{mol} \mathrm{H} 89 \mathrm{I}^{-1}$ and then further diluted fivefold with BWW containing

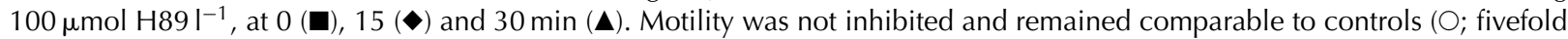
dilution with BWW alone). Values are mean \pm SEM for (a) 5, (b) 4, (c) 3 and (d) 3 animals.

motile $(P<0.01)$. A lower sperm motility $(P<0.01)$ was activated in samples diluted fivefold with Hepes-sucrose $\left(350 \mathrm{mOsmol} \mathrm{I}^{-1}\right)$, but this motility virtually ceased within 15 min (Fig. 2a). Sperm motility was not activated by dilution with plasma from the cauda epididymidis (Fig. 2a). or seminal vesicle fluid (Fig. 2b). The effect of plasma from the cauda epididymidis was examined further by activating spermatozoa in a $1 \mu \mathrm{l}$ sample of semen from the cauda epididymidis by fivefold dilution with BWW then further diluting the sample 20-fold with plasma 15 min later. This reduced sperm motility significantly within $15 \mathrm{~min}$ of application $(P<0.01)$ and spermatozoa were immotile at $60 \mathrm{~min}$ (Fig. 2C).

The pathway for intracellular signal transduction was examined to determine whether inhibitors of PKA activity could prevent or attenuate sperm motility activated by fivefold dilution. The cell-permeable inhibitor of PKA,
$\mathrm{H} 89$ (20, 100 or $500 \mu \mathrm{mol} \mathrm{I}^{-1}$ ), or the broad-spectrum kinase inhibitor, staurosporine (5 or $25 \mu \mathrm{mol} \mathrm{I}^{-1}$ ) was included in BWW. However, dilution with BWW containing these reagents did not prevent activation. The effect of inhibiting PKA was investigated further by allowing $\mathrm{H} 89$ time to access inhibitory sites within the cells by diluting a $1 \mu \mathrm{l}$ sample of semen from the cauda epididymidis by 1.05 -fold with sucrose containing $20 \mu \mathrm{mol} \mathrm{H} 89 \mathrm{I}^{-1}$, and then further diluting the sample fivefold with BWW containing $100 \mu \mathrm{mol} \mathrm{H} 89 \mathrm{I}^{-1}$ at 0 , 15 and 30 min after the initial addition of H89. Sperm motility was not inhibited by this treatment (Fig. 2d).

\section{cAMP content of spermatozoa}

The intracellular cAMP content of spermatozoa was determined to assess the involvement of a cAMP 


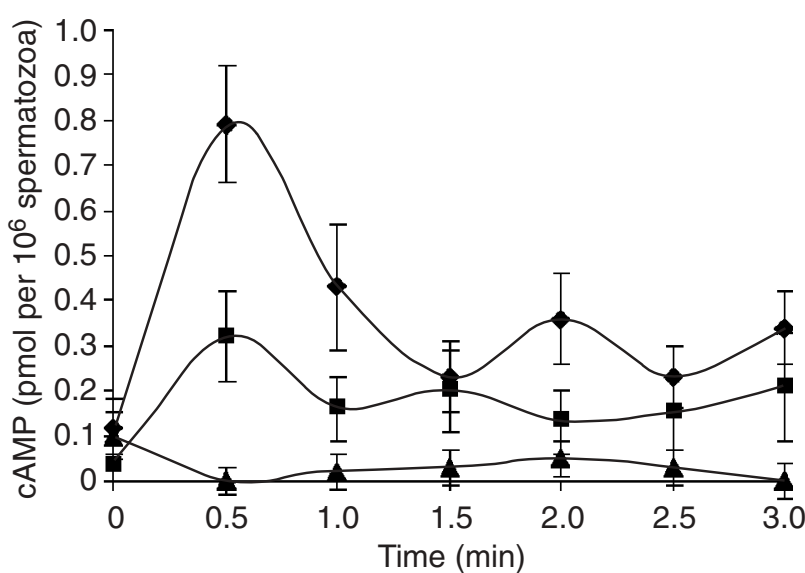

Fig. 3. The intracellular cAMP content in spermatozoa after $1 \mu \mathrm{l}$ samples of semen from the cauda epididymidis were diluted fivefold with BWW medium containing $1.8 \mathrm{mmol} \mathrm{Ca}{ }^{2+} 1^{-1}(\diamond)$, BWW containing $0 \mathrm{mmol} \mathrm{Ca}{ }^{2+} 1^{-1}(\mathbf{\Delta})$ or 1.05 -fold with $300 \mathrm{mmol}$ sucrose $1^{-1}$ containing $8 \mathrm{mmol} \mathrm{Ca}^{2+} 1^{-1}(\boldsymbol{\square})$. Values are mean \pm SEM for six animals.

signalling pathway in activation of sperm motility. A fivefold dilution of spermatozoa from the cauda epididymidis with BWW stimulated a sevenfold increase in CAMP in spermatozoa during the first $60 \mathrm{~s}$ of motility activation, compared with non-activated spermatozoa $(P<0.01)$. However, there was no increase in cAMP when $\mathrm{Ca}^{2+}$ was omitted from the BWW (Fig. 3) or when samples were diluted with plasma from the cauda epididymidis (data not shown). Diluting semen from the cauda epididymidis 1.05 -fold with $300 \mathrm{mmol}$ sucrose $\mathrm{I}^{-1}$ containing $8 \mathrm{mmol} \mathrm{Ca}{ }^{2+} \mathrm{I}^{-1}$ caused a significant increase in intracellular cAMP in spermatozoa after $30 \mathrm{~s}$ $(P<0.01)$, compared with non-activated samples. This effect could not be mimicked by $\mathrm{Mg}^{2+}$ at a final concentration of $8 \mathrm{mmol} \mathrm{I}^{-1}$ or $300 \mathrm{mmol}^{\text {sucrose }}{ }^{-1}$ (data not shown).

\section{Discussion}

This analysis of mechanisms of activation of sperm motility in rats used a model that allows the effects of dilution to be examined independently of the constituents of the diluent. The results shed light on potential mechanisms of activation of sperm motility and second messenger signal transduction pathways used by spermatozoa from the cauda epididymidis during the initiation of motility. dbcGMP, sodium chloride and energy substrates do not activate motility. ROS, postulated to increase $\mathrm{pH}_{(\mathrm{i})}$ and thereby act as the first messenger in the activation cascade (Aitken, 2000), too had no effect on these cells. If sperm adenylyl cyclase is involved in the initial burst of motility, it does not appear to be influenced by bicarbonate (Okamura et al., 1985), because the addition of this anion failed to activate sperm movement under the conditions used in this study. This may indicate that the soluble form of adenylyl cyclase, reported in spermatozoa to be responsive to bicarbonate (Chen et al., 2000), is not the adenylyl cyclase involved in the initiation of motility in immotile spermatozoa. Similarly, forskolin, which targets the catalytic domain of most transmembrane adenylyl cyclases (Tang and Hurley, 1998) also failed to activate motility in these cells. Pertussis or cholera toxins, which catalyse the covalent incorporation of ADP-ribose into $\alpha$ subunits of GTPbinding proteins (Freissmuth and Gilman, 1989), also had no effect on activation of sperm motility in this population of spermatozoa (present study). However, reagents such as dbcAMP, PTX and $\mathrm{Ca}^{2+}$, which directly target cAMP and $\mathrm{Ca}^{2+}$-signalling pathways, activated sperm motility without significant dilution of epididymal semen (present study).

The immobilin hypothesis has been put forward to account for sperm quiescence in the cauda epididymidis of rats. The basic tenet of this proposal is that caudal spermatozoa are immobilized by the mechanical constraint imposed by the high viscoelasticity of plasma from the cauda epididymidis, the dilution of which permits motility (Usselman and Cone, 1983). However, the present study and earlier work (Armstrong et al., 1994; Murdoch et al., 1999) has clearly demonstrated that activation of sperm motility can occur in the absence of dilution. Moreover, only plasma from the cauda epididymidis of rats, hamsters and to a much lesser extent guinea pigs, contain immobilin, yet spermatozoa from other species including mice, dogs, elephants and tammar wallabies, are quiescent in situ in the absence of immobilin (Jones, 1973, 1978; Carr et al., 1985; Clulow et al., 1992; Jones and Murdoch, 1996). This finding indicates that viscosity alone does not account for quiescence during storage. However, this highly viscous fluid doubtless retards motility in samples activated in the absence of dilution, compared with those activated by fivefold dilution.

As the motility induced by directly targetting cAMP and $\mathrm{Ca}^{2+}$ pathways ceased within 30-60 min, additional energy substrates were provided to test the hypothesis that these factors might be rate-limiting. The inclusion of glucose or acetate with the dbcAMP extended motility for a short time only, indicating that energy substrate availability is not rate-limiting. Furthermore, a second application of dbcAMP failed to re-activate motility, indicating that the cAMP pathway is completely refractory after the initial stimulus occurs. This putative refractory state may be due to a decrease in $\mathrm{pH}_{(\mathrm{i})}$. For example, in the absence of dilution, protons produced as a result of respiration may acidify the sperm cytoplasm, to the point where motility becomes suppressed $60 \mathrm{~min}$ after activation. Indeed, motility suppression in acidic media has been demonstrated in spermatozoa from bulls (Carr et al., 1985), wallabies (Clulow et al., 1992) and mice (Tash and Bracho, 1998). Upon dilution with a 
balanced salt solution this quiescence was reversed, such that vigorous motility can be activated and maintained over time (present study). Notwithstanding, motility was activated without an apparent increase in $\mathrm{pH}_{(\mathrm{i})}$, indicating that cytoplasmic alkalinization is not essential to activate motility in rat spermatozoa from the cauda epididymidis.

In the present study, the finding that $\mathrm{Ca}^{2+}$ activated motility, and increased intracellular CAMP, indicates that this ion has a central role in activation of sperm motility in spermatozoa from the cauda epididymidis. This was further emphasized when vigorous motility was activated and sustained by dilution with BWW containing $\mathrm{Ca}^{2+}$ but impaired when $\mathrm{Ca}^{2+}$ was omitted from the BWW. The sperm motility activated by dilution with prostatic fluid may also be attributed to the availability of $\mathrm{Ca}^{2+}$, present in prostasomes (Palmerini et al., 1999), because the intracellular concentration of $\mathrm{Ca}^{2+}$ has been shown to increase in human spermatozoa after fusion with prostasomes (Kravets et al., 2000).

However, it is possible that calcium is not the only factor influencing motility activation, as lower motility was induced by dilution in $\mathrm{Ca}^{2+}$-free $\mathrm{BWW}$ or a simple solution such as Hepes-sucrose, devoid of ionic support or energy substrates (present study). Although speculative, dilution may change the gradients of a number of ions in the extracellular fluid. This would cause a voltage change across the plasma membrane, and this may be activating. In sea urchin spermatozoa, altering membrane polarity activates $\mathrm{Na}^{+}-\mathrm{H}^{+}$exchangers (Christen et al., 1982); in carp spermatozoa it facilitates activation of $\mathrm{Ca}^{2+}$ channels (Krasznai et al., 2000); it also triggers a cascade of events associated with activation of motility in trout spermatozoa (Boitano and Omoto, 1991). The fact that dilution with plasma from the cauda epididymidis did not activate sperm motility in the present study is entirely consistent with this notion, because dilution with this fluid would not affect ionic gradients surrounding the spermatozoa. Further plasma may return the sperm membrane to its resting state because vigorous motility was inhibited by a further dilution with plasma in the present study. A plausible alternative explanation may be that plasma from the cauda epididymidis contains an inhibitor of sperm motility. Because plasma from the cauda epididymidis inhibits the motility of spermatozoa already activated with BWW, a putative inhibitor may be capable of counteracting the stimulatory effects of calcium or dilution, possibly by interacting with $\mathrm{Ca}^{2+}$ channels in the sperm plasma membrane.

Results from the present study show that addition of $\mathrm{Ca}^{2+}$ is an absolute requirement for increasing intracellular cAMP in rat spermatozoa from the cauda epididymidis. An increase in intracellular cAMP was also demonstrated in hamster spermatozoa when motility was activated by dilution with a buffer containing $\mathrm{Ca}^{2+}$ (Morton et al., 1974). However, in that study the effects of dilution and $\mathrm{Ca}^{2+}$ were confounded. In contrast, the model of activation used by the present study allows for the effects of dilution on motility to be examined independently of the composition of the diluent. As a consequence, the transient increase in intracellular cAMP in cells to which $\mathrm{Ca}^{2+}$ is added can be attributed directly to the $\mathrm{Ca}^{2+}$. Moreover, the effect is not a general feature of divalent cations because there is no increase in CAMP when $\mathrm{Mg}^{2+}$ is added to spermatozoa under identical conditions. Together these data indicate that the rapid increase in CAMP in spermatozoa undergoing motility activation is $\mathrm{Ca}^{2+}$-dependent. To our knowledge, this is the first definitive measure of a $\mathrm{Ca}^{2+}$-dependent increase in intracellular cAMP associated with activation of motility in spermatozoa from mammalian cauda epididymidis. One possible interpretation of this data is that $\mathrm{Ca}^{2+}$ directly activates the sperm adenylyl cyclase involved in motility. Currently three adenylyl cyclases are known to be stimulated by $\mathrm{Ca}^{2+}$ (types I, III and VIII; Cooper et al., 1995). Adenylyl cyclase III has been demonstrated to be present in the acrosomal membrane of rat germ cells (Defer et al., 1998), but not on the sperm tail.

The mechanism(s) by which cAMP stimulates motility is still open to question. In the present study, motility could not be inhibited using a PKA-selective inhibitor, H89. One possible reason for the lack of inhibition by $\mathrm{H} 89$ is that it failed to cross the cell membrane and access inhibitory sites within the spermatozoa. Although this study does not provide definitive evidence that $\mathrm{H} 89$ can cross the cell membrane, it was purchased as a cell-permeable reagent. For this reason we have assumed that access to binding sites is not a limiting factor in this study. Another possibility is that $\mathrm{H} 89$ attenuated motility at amounts below those that could be detected using the current protocol for scoring sperm motility. However, the fact that moderate to low sperm motility can be activated in these cells without increasing CAMP indicates that phosphorylation of flagella proteins mediated by PKA is not essential to activate sperm motility in cauda epididymidis in rats. Additional support for this notion is derived from a study by Burton et al. (1999). Type II PKA, reported to be the primary isoform of PKA in mature sperm flagellum (Lieberman et al., 1988; Vijayaraghavan et al., 1997), was thought to bind cAMP and thus stimulate motility. However, in mouse spermatozoa, targetted disruption

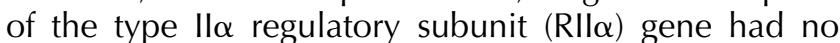
deleterious effects on motility (Burton et al., 1999).

An alternative possibility to CAMP mediating PKA activation is that CAMP may interact directly with a target molecule, independently of PKA activation. Synergy between CAMP and $\mathrm{Ca}^{2+}$ signalling pathways has been demonstrated in other types of cell (Cooper et al., 1995; Mons et al., 1998) and in spermatozoa by this study. It is possible that cyclic nucleotide gated channels, located on the sperm tail (Weyand et al., 1994; Wiesner et al., 
1998) or indeed, the novel sperm ion channel, Cat Sper (Ren et al., 2001), similarly located (Quill et al., 2001), are potential targets for cAMP. Both serve as entry points for $\mathrm{Ca}^{2+}$ in activated spermatozoa. Furthermore, because exposure of spermatozoa to $\mathrm{Ca}^{2+}$ increased intracellular CAMP within $60 \mathrm{~s}$, and application of cAMP to mouse spermatozoa increased intracellular $\mathrm{Ca}^{2+}$ over a similar time course (Ren et al., 2001), it seems plausible that these channels form part of a regulatory feedback mechanism to alter the amounts of these two key signalling molecules in spermatozoa and control the initiation of motility.

In conclusion, the CAMP and $\mathrm{Ca}^{2+}$ signal transduction pathways are involved in activation of motility in immotile spermatozoa from the cauda epididymidis. Motility can be activated by dilution in $\mathrm{Ca}^{2+}$-free media and it is possible that this may be due to voltage change across the plasma membrane induced by dilution. However, the presence of $\mathrm{Ca}^{2+}$ is essential to increase sperm motility and intracellular cAMP. Moderate to low motility can be activated in these cells without increasing cAMP, indicating that PKA-mediated phosphorylation of flagella proteins is not essential for activating motility, and leading to the suggestion that CAMP targets alternative molecules involved in the activation process in immotile spermatozoa from the cauda epididymidis from rats.

The work was supported by a grant from the Australian Research Council.

\section{References}

Aitken JR (2000) Possible redox regulation of spermatozoa motility activation Journal of Andrology 21 491-496

Armstrong VL, Clulow J, Murdoch RN and Jones RC (1994) Intracellular signal transduction mechanisms of rat epididymal spermatozoa and their relationship to motility and metabolism Molecular Reproduction and Development 38 77-84

Beltran C, Zapata O and Darszon A (1996) Membrane potential regulates sea urchin sperm adenylyl cyclase Biochemistry 35 7591-7598

Biggers JD, Whitten WK and Whittingham DG (1971) In Methods in Mammalian Embryology pp 86-94 Ed. JC Daniel. Freeman Press, San Francisco

Boitano S and Omoto CK (1991) Membrane hyperpolarization activates trout sperm without an increase in intracellular $\mathrm{pH}$ Journal of Cell Science 98 343-349

Bracho GE, Fritch JJ and Tash JS (1998) Identification of flagellar proteins that initiate the activation of sperm motility in vivo. Biochemical and Biophysical Research Communications 242 231-237

Burton KA, Treash-Osio B, Muller CH, Dunphy EL and McKnight GS (1999) Deletion of type Il $\alpha$ regulatory subunit delocalized protein kinase A in mouse sperm without affecting motility or fertilization Journal of Biological Chemistry 27424 131-24 136

Carr DW, Ussleman MC and Acott TS (1985) Effects of pH, lactate and viscoelastic drag on sperm motility: a species comparison Biology of Reproduction 33 588-595

Chen Y, Cann MJ, Litvin TN, lourgenko V, Sinclair ML, Levin LR and Buck J (2000) Soluble adenylyl cyclase as an evolutionarily conserved bicarbonate sensor Science 289 625-628

Christen R, Shackmann RW and Shapiro BM (1982) Elevation of the internal $\mathrm{pH}$ activated respiration and motility of sperm of the sea urchin Strogylocentrotus purpuratus. Journal of Biological Chemistry 257 $14881-14890$

Clulow J, Jones RC and Murdoch RN (1992) Maturation and regulation of the motility of spermatozoa in the epididymis of the tammar wallaby (Macropus eugenii) Journal of Reproduction and Fertility 94 295-303

Cooper MF, Mons N and Karpen JW (1995) Adenylyl cyclases and the interaction between calcium and cAMP signalling Nature 372 421-424

Darszon A, Labarca P, Nishigaki T and Espinosa F (1999) lon channels in spermatozoa physiology Physiological Reviews 79 481-510

Defer N, Marinx O, Poyard M, Lienard MO, Jegou B and Hanoune J (1998) The olfactory adenylyl cyclase type 3 is expressed in male germ cells FEBS Letters 424 216-220

Freissmuth M and Gilman AG (1989) Mutations of $\mathrm{G}_{\mathrm{s}^{\alpha}}$ designed to alter the reactivity of the protein with bacterial toxins. Substitutions at $\mathrm{ARG}^{187}$ result in loss of GTPase activity Journal of Biological Chemistry 264 21 907-21 914

Hamamah S and Gatti J (1998) Role of the ionic environment and internal $\mathrm{pH}$ on sperm activity Human Reproduction 13 20-30

Jones RC (1973) Collection, motility and storage of spermatozoa from the African elephant Loxodonta africana. Nature 243 38-39

Jones $\mathbf{R}$ (1978) Comparative biochemistry of mammalian epididymal plasma Comparative Biochemistry and Physiology 61B 365-370

Jones RC and Murdoch RN (1996) Regulation of the motility and metabolism of spermatozoa for storage in the epididymis of eutherian and marsupial mammals Reproduction, Fertility and Development 8 553-568

Krasznai Z, Teréz M, Izumi H, Damjanovich S, Balkay L, Trón L and Morisawa M (2000) Membrane hyperpolarization removes inactivation of $\mathrm{Ca}^{2+}$ channels, leading to $\mathrm{Ca}^{2+}$ influx and subsequent initiation of spermatozoa motility in the common carp Proceedings National Academy of Sciences USA 97 2052-2057

Kravets FG, Lee J, Singh B, Trocchia A, Pentyala SN and Khan SA (2000) Prostasomes: current concepts Prostate 43 169-174

Lieberman SJ, Wasco W, MacLeod J, Satir P and Orr GA (1988) Immunogold localization of the regulatory subunit of a type II cAMP-dependent protein kinase tightly associated with mammalian sperm flagella Journal of Cell Biology 107 1089-1816

Mons N, Decorte L, Jaffard R and Cooper DM (1998) $\mathrm{Ca}^{2+}$-sensitive adenylyl cyclases, key integrators of cellular signalling Life Science $\mathbf{6 2}$ 1647-1652

Morton B, Harrigan-Lum L, Albagli L and Jooss T (1974) The activation of motility in quiescent hamster sperm from the epididymis by calcium and cyclic nucleotides Biochemical and Biophysical Research Communications 56 372-379

Murdoch RN, Armstrong VL, Clulow J and Jones RC (1999) Relationship between motility and oxygen consumption of sperm from the cauda epididymides of the rat Reproduction, Fertility and Development $\mathbf{1 1}$ 87-94

Okamura N, Tajima Y, Soejima A, Masuda H and Sugita Y (1985) Sodium bicarbonate in seminal plasma stimulates the motility of mammalian spermatozoa through direct activation of adenylyl cyclase Journal of Biological Chemistry $2609699-9705$

Palmerini CA, Carlini E, Nicolucci A and Arienti G (1999) Increase of human spermatozoa intracellular $\mathrm{Ca}^{2+}$ concentration after fusion with prostasomes Cell Calcium 25 291-296

Pholpramool C, Zupp JL and Setchell BP (1985) Motility of undiluted bull epididymal spermatozoa collected by micropuncture Journal of Reproduction and Fertility 75 413-420

Quill TA, Ren D, Clapham DE and Garbers DL (2001) A voltage-gated ion channel expressed specifically in spermatozoa Proceedings National Academy of Sciences USA 9812 527-12 531

Ren D, Navarro B, Perez G, Jackson AC, Hsu S, Shi Q, Tilly JL and Clapham DE (2001) A sperm ion channel required for sperm motility and male fertility Nature 413 603-609

Tang WJ and Hurley JH (1998) Catalytic mechanism and regulation of mammalian adenylyl cyclases Molecular Pharmacology 54 231-240

Tash JS and Bracho GE (1998) Identification of phosphoproteins coupled to initiation of motility in live epididymal mouse sperm Biochemistry and Biophysical Research Communications 251 557-563 
Usselman MC and Cone RA (1983) Rat spermatozoa are mechanically immobilized in the caudal epididymis by 'immobilin', a high molecular weight glycoprotein Biology of Reproduction 29 1241-1253

Vijayaraghavan S, Olson GE, NagDas S, Winfrey VP and Carr DW (1997) Subcellular localization of the regulatory subunits of cyclic adenosine $3^{\prime}, 5^{\prime}$-monophosphate-dependent protein kinase in bovine spermatozoa Biology of Reproduction 57 1517-1523

Weyand IM, Godde S, Frings J, Weiner F, Muller W, Altenhofen H, Hatt H and Kaupp UB (1994) Cloning and functional expression of a cyclicnucleotide-gated channel from mammalian sperm Nature 368 859-863
Wiesner B, Weiner J, Middendorff R, Hagen V, Kaupp UB and Weyand I (1998) Cyclic nucleotide-gated channels on the flagellum control $\mathrm{Ca}^{2+}$ entry into sperm Journal of Cell Biology 142 473-484

Received 20 May 2002.

First decision 7 August 2002.

Revised manuscript received 1 October 2002.

Accepted 5 November 2002. 